\title{
Infrared measurements in the Arctic using two Atmospheric Emitted Radiance Interferometers
}

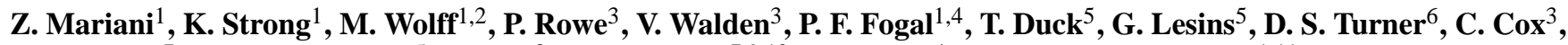 \\ E. Eloranta ${ }^{7}$, J. R. Drummond ${ }^{5}$, C. Roy $^{8}$, D. D. Turner ${ }^{7,9,10}$, D. Hudak ${ }^{4}$, and I. A. Lindenmaier ${ }^{1,11}$ \\ ${ }^{1}$ Department of Physics, University of Toronto, Toronto, ON, Canada \\ ${ }^{2}$ The Norwegian Meteorological Institute, Oslo, Norway \\ ${ }^{3}$ Department of Geography, University of Idaho, Idaho, USA \\ ${ }^{4}$ Air Quality Research Division, Environment Canada, Downsview, Canada \\ ${ }^{5}$ Department of Physics, Dalhousie University, Halifax, NS, Canada \\ ${ }^{6}$ Data Assimilation and Satellite Meteorology Research Section, Environment Canada, Downsview, ON, Canada \\ ${ }^{7}$ University of Wisconsin Space Science and Engineering Centre, Madison, Wisconsin, USA \\ ${ }^{8}$ ABB Bomem, Quebec City, Canada \\ ${ }^{9}$ Department of Atmospheric and Oceanic Sciences, University of Wisconsin, Madison, Wisconsin, USA \\ ${ }^{10}$ NOAA/National Severe Storms Laboratory, Norman, Oklahoma, USA \\ ${ }^{11}$ Thunder Bay Regional Research Institute, Thunder Bay, ON, Canada
}

Correspondence to: Z. Mariani (zmariani@atmosp.physics.utoronto.ca), K. Strong (strong@atmosp.physics.utoronto.ca), M. Wolff (mareile.wolff@met.no), P. Rowe (prowe@ harbornet.com), V. Walden (vonw@uidaho.edu),

P. F. Fogal (pierre.fogal@utoronto.ca), T. Duck (tom.duck@dal.ca), G. Lesins (glen.lesins@dal.ca),

D.S. Turner (shawn.turner@ec.gc.ca), C. Cox (ccox@vandals.uidaho.edu), E. Eloranta (eloranta@ssec.wisc.edu),

J. R. Drummond (james.drummond@dal.ca), C. Roy (claude.b.roy@ca.abb.com), D. D. Turner(dave.turner@noaa.gov),

D. Hudak (david.hudak@ec.gc.ca), I. A. Lindenmaier (ialindenmaier@atmosp.physics.utoronto.ca)

Received: 3 October 2011 - Published in Atmos. Meas. Tech. Discuss.: 24 October 2011

Revised: 23 January 2012 - Accepted: 25 January 2012 - Published: 6 February 2012

\begin{abstract}
The Extended-range Atmospheric Emitted Radiance Interferometer (E-AERI) is a moderate resolution $\left(1 \mathrm{~cm}^{-1}\right)$ Fourier transform infrared spectrometer for measuring the absolute downwelling infrared spectral radiance from the atmosphere between 400 and $3000 \mathrm{~cm}^{-1}$. The extended spectral range of the instrument permits monitoring of the $400-550 \mathrm{~cm}^{-1}(20-25 \mu \mathrm{m})$ region, where most of the infrared surface cooling currently occurs in the dry air of the Arctic. Spectra from the E-AERI have the potential to provide information about radiative balance, trace gases, and cloud properties in the Canadian high Arctic. Calibration, performance evaluation, and certification of the E-AERI were performed at the University of Wisconsin Space Science and Engineering Centre from September to October 2008. The instrument was then installed at the Polar Environment Atmospheric Research Laboratory (PEARL) Ridge Lab (610 m altitude) at Eureka, Nunavut, in October 2008, where it acquired one year of data. Measurements are taken every seven minutes year-round, including polar night when the solar-viewing spectrometers at PEARL are not operated.
\end{abstract}

A similar instrument, the University of Idaho's Polar AERI (P-AERI), was installed at the Zero-altitude PEARL Auxiliary Laboratory (OPAL), $15 \mathrm{~km}$ away from the PEARL Ridge Lab, from March 2006 to June 2009. During the period of overlap, these two instruments provided calibrated radiance measurements from two altitudes. A fast line-by-line radiative transfer model is used to simulate the downwelling radiance at both altitudes; the largest differences (simulationmeasurement) occur in spectral regions strongly influenced by atmospheric temperature and/or water vapour. The two AERI instruments at close proximity but located at two different altitudes are well-suited for investigating cloud forcing. As an example, it is shown that a thin, low ice cloud resulted in a $6 \%$ increase in irradiance. The presence of clouds creates a large surface radiative forcing in the Arctic, particularly in the $750-1200 \mathrm{~cm}^{-1}$ region where the downwelling radiance is several times greater than clear-sky radiances, which is significantly larger than in other more humid regions. 


\section{Introduction}

The Canadian Network for the Detection of Atmospheric Change (CANDAC) has equipped the Polar Environment Atmospheric Research Laboratory (PEARL) at an altitude of $610 \mathrm{~m}$ at Eureka, Nunavut $\left(80^{\circ} \mathrm{N}, 86^{\circ} \mathrm{W}\right)$ for measurements during International Polar Year (IPY, project 196) and beyond. One of the instruments at PEARL is the Extendedrange Atmospheric Emitted Radiance Interferometer (the EAERI). This instrument measures the absolute downwelling infrared radiation spectrum for studies of the Arctic radiation budget and atmospheric composition. The E-AERI was installed in October 2008 and acquired one full year of measurements at the PEARL Ridge Lab. In September 2009, the E-AERI was moved to the Zero-altitude PEARL Auxiliary Laboratory (OPAL), which is $15 \mathrm{~km}$ away from the PEARL Ridge Lab. Measurements of downwelling radiance from an altitude of $10 \mathrm{~m}$ continue to be taken at OPAL to determine concentrations of tropospheric trace gases and investigate infrared cooling in the $20-\mu \mathrm{m}$ region.

AERI instruments were developed at the University of Wisconsin Space Science and Engineering Centre (UWSSEC) from 1989 to 1998 using an MR100 spectroradiometer developed from an MB-120 interferometer designed for industrial applications by ABB Bomem Inc. of Quebec, Canada (Collard et al., 1995). A suite of AERI instruments was then developed for the Atmospheric Radiation Measurement (ARM) (DOE, 1990) Climate Research Facility sites in the Southern Great Plains (Oklahoma), the North Slope of Alaska, and the Tropical Western Pacific (Stokes and Schwartz, 1994; Knuteson et al., 2004a). In addition to the downwelling radiance measurements, measurements of the atmospheric state (e.g., radiosonde profiles) are made at these sites allowing for radiance simulations (Ellingson and Wiscombe, 1996). These AERI systems have collected over a decade of data at the ARM sites and have been used to generate climatologies in downwelling infrared radiance (Turner and Gero, 2011) and to investigate long-term trends (Gero and Turner, 2011). In addition to the ARM AERIs, other AERI instruments include the Marine AERI (M-AERI) (Minnett, 2001), the University of Denver's high-resolution AERI-X deployed at the PEARL Ridge Lab from 1994-2002 (Olson et al., 1996), and the University of Idaho's Polar AERI (P-AERI) (Walden et al., 2005; Rowe et al., 2008).

The newest generation AERI (e.g., the E-AERI installed at PEARL) was developed by ABB under commercial license from UW-SSEC. These AERIs incorporate the newest generation of ABB Bomem's Fourier Transform Infrared (FTIR) spectroradiometer, a University of Wisconsin (UW) blackbody cavity, the latest signal conditioning units, and a new detector/Stirling cooler with an extended lifetime. The new AERI configuration allows in-field replacement of the Stirling cooler and metrology laser. The software has been updated with a combination of ABB software for data acquisition and instrument communication/control interface, and
UW software for post-processing and atmospheric science functions to ease future evolution of hardware and software by each party. The new AERIs also include front-end and back-end enclosures that protect against atmospheric precipitation and temperature variation, respectively. In addition to these modifications, the E-AERI extends the spectral coverage range of a standard AERI $\left(550-3000 \mathrm{~cm}^{-1}\right)$ to $400-$ $3000 \mathrm{~cm}^{-1}$.

The thermal emitted radiance measured by the E-AERI is primarily dependent on the water vapour content and temperature of the atmosphere in cloud-free scenes. Therefore, temperature and humidity profiles of the planetary boundary layer can be retrieved from AERI and E-AERI spectra, as demonstrated in Feltz et al. (1998), Smith et al. (1999), and Turner et al. (2000). This allows for high-temporalresolution records and analyses of temperature and water vapour changes due to mesoscale meteorological features. The sampling interval of approximately seven minutes allows the study of short-term meteorological phenomena in the lower atmosphere, e.g., inversion developments, cloud effects, and front passages.

The spectral range of the E-AERI covers the so-called "dirty window" (around $400 \mathrm{~cm}^{-1}$, or $20 \mu \mathrm{m}$ ), where most of the infrared cooling currently occurs in the dry air of the Arctic. The importance of the far infrared (IR) for midto-upper tropospheric cooling has been well demonstrated in Clough et al. (1992). Due to climate change, the water vapour content of the Arctic atmosphere is expected to increase, with a corresponding change in downwelling radiance. Such a regime shift should be visible in the E-AERI data record. In addition, the far IR is important for cloud thermodynamic phase determination, as demonstrated by Rathke et al. (2002). A previous extended-range version of the AERI system was deployed at the Surface Heat Budget of the Arctic Ocean Ice Station in 1997; this AERI was used to investigate the far infrared $\mathrm{H}_{2} \mathrm{O}$ continuum (Tobin, 1999) and to characterize the phase and microphysical properties of mixed phase Arctic boundary layer clouds (Turner, 2005).

Retrievals of total columns of various trace gases are currently being evaluated using a prototype version of the retrieval algorithm SFIT2 (Pougatchev et al., 1995; Rinsland et al., 1998) modified to analyze emission features. Total columns of $\mathrm{O}_{3}, \mathrm{CO}, \mathrm{CO}_{2}, \mathrm{CH}_{4}, \mathrm{~N}_{2} \mathrm{O}, \mathrm{HCN}$, and $\mathrm{C}_{2} \mathrm{H}_{4}$ using SFIT2 can be retrieved from E-AERI spectra during clearsky conditions. Recently, retrievals of CO with high sensitivity to the lower troposphere have been demonstrated for the AERI systems (Yurganov et al., 2010). In contrast to solar absorption measurements of atmospheric trace gases, which depend on sunlit clear-sky conditions, the use of emission spectra allows measurements year-round (except during precipitation events or when clouds are present). This capability allows the E-AERI to provide temporal coverage throughout the four months of polar night, when the PEARL Bruker 125HR solar absorption FTIR spectrometer is not operated (Batchelor et al., 2009). 
The installation of the E-AERI at PEARL was preceded by the P-AERI, which was deployed at OPAL from March 2006 to June 2009 (and was subsequently deployed in Summit, Greenland). The two instruments are similar, but the P-AERI does not provide spectral coverage below $500 \mathrm{~cm}^{-1}$. In addition, the E-AERI was housed in the PEARL Ridge lab at an altitude of $610 \mathrm{~m}$, while the P-AERI was operated $15 \mathrm{~km}$ away at an altitude of $10 \mathrm{~m}$. Having two AERI instruments close in proximity at these altitudes presents an opportunity for investigation of the lowest $600 \mathrm{~m}$ of atmosphere, potentially including differences in trace gases, aerosols, and lowlevel liquid and ice clouds. Other instrumentation at OPAL that provides information for cloud studies includes the Millimeter Wave Cloud Radar (MMCR), which measures equivalent radar reflectivity, Doppler velocity, spectral width, and Doppler spectra over 2-s intervals, and UW's Arctic High Spectral Resolution Lidar (AHSRL), which measures aerosol backscatter cross section and particulate circular depolarization ratio (Eloranta, 2005). These can be used to determine cloud heights, thicknesses, composition, internal structure and vertical motions with high vertical and temporal resolution.

In this paper, we present the E-AERI instrument, detailing its operation, calibration, and noise characteristics, and show that measured spectra are comparable to those of other AERI instruments. Following this is a first look at the spectra recorded by E-AERI at the PEARL Ridge Lab, including examples of clear and cloudy skies, investigation of the lower $600 \mathrm{~m}$ making use of the P-AERI measurements for both the full overlap period October 2008 to April 2009 and for an ice cloud case study, and comparisons to simulated radiances. A description of the E-AERI hardware, performance, and software and operational parameters are presented in Sect. 2 . Section 3 describes the instrument's performance, including calibration results obtained at UW, side-by-side comparisons between the E-AERI and UW's AERI-07 and AERIBago (AERI-03) instruments, and side-by-side comparisons between the E- and P-AERI instruments at sea-level. Section 4 presents clear and cloudy sky E-AERI measurements, comparisons to radiance simulations from a fast line-by-line radiative transfer model, radiance residuals between the EAERI (at $610 \mathrm{~m}$ ) and P-AERI (at $10 \mathrm{~m}$ ), and an analysis of the radiative impact of a low-level ice cloud at the two measurement sites. A summary of conclusions is given in Sect. 5 .

\section{Instrument design}

\subsection{Instrument hardware}

The E-AERI is composed of three distinct parts: the frontend (housing the optics), the back-end (housing the electronic modules and interferometer), and the computer (standard off-the-shelf laptop). The front-end optics consists of two blackbodies and the scene mirror. The scene mirror has a gold reflecting surface and is mounted at $45^{\circ}$ to the motor rotation axis, which is in turn positioned coincident with the interferometer input optical axis. This configuration allows different views: nadir, zenith (sky), Ambient Blackbody (AB) and Hot Blackbody (HB). Steady air flow is provided by a fan within the front-end enclosure to push dust and dirt particles away from the scene mirror. Seasonal cleaning of the scene mirror is performed by on-site operators to remove any accumulated dust and dirt, maintaining the mirror's reflectivity. The scene mirror directs IR radiation through an IR-transmitting optical window into the interferometer at the back-end portion of the instrument.

The interferometer is an MR-300 series Fourier Transform Spectrometer (FTS), installed in the back-end portion of the instrument. The maximum optical path difference is $1 \mathrm{~cm}$, providing a spectral resolution of $1 \mathrm{~cm}^{-1}$. Two IR-detecting channels are supported by an extended-range photoconductive mercury cadmium telluride (MCT) detector coupled with a photovoltaic indium antimonide ( $\mathrm{InSb}$ ) detector mounted in a sandwich configuration. The detectors are housed in a dewar and cooled below $70 \mathrm{~K}$ by a linear Stirling-cycle cryocooler. Electronic modules (signal conditioning electronics, blackbody temperature controller, and Stirling cooler support electronics) are mounted in the back-end. The temperatures of the back-end components are kept stable through a temperature control unit.

\subsection{Instrument enclosure}

The instrument is designed to be configured as stand-alone or mounted thru-wall. An enclosure protects the instrument against sun, rain, snow, wind, sand, etc. Currently, the instrument is removed from its mobile base for thru-wall installation and is fixed on a mounting platform. The photographs in Fig. 1 were taken after the E-AERI was installed using the thru-wall configuration in a penthouse on the roof of the PEARL Ridge Lab. The front-end is outside the building, detached from the back-end and sealed to the external wall (see arrow in left side of Fig. 1), while the back-end is inside the building (right side of Fig. 1).

The electronics and the FTS contained within the backend enclosure (shown opened in Fig. 1) can operate between $-30^{\circ} \mathrm{C}$ and $+40^{\circ} \mathrm{C}$. A temperature control unit maintains it at a constant temperature. The front-end enclosure protects against precipitation (both rain and snow) but is not stabilized in temperature; it is free running near the ambient temperature. Two Vaisala DRD11A precipitation sensors (one elevated and one flush with the enclosure) detect any precipitation occurring. A hatch, actuated by the precipitation sensors or directly by the user or instrument commanding script, can be closed to protect the optical head, or opened to look at the atmosphere. In the presence of precipitation, the system will automatically close the hatch and turn itself off in a self-protection mode that does not allow sky measurement. After the precipitation ends, the system returns to 


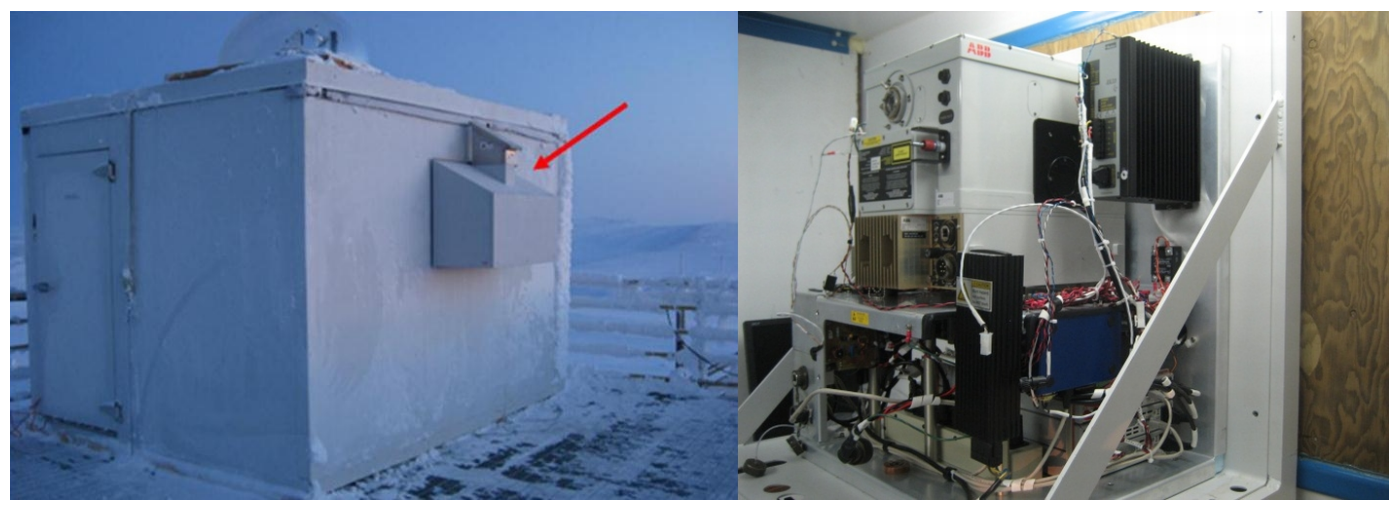

Fig. 1. Exterior (left panel, red arrow) and interior (right panel) views of the E-AERI installed on the roof of the PEARL Ridge Lab using the thru-wall configuration. Left panel: front-end portion of the E-AERI instrument housing the optics; the hatch is closed during precipitation events (photo: Stephane Lantagne). Right panel: the back-end portion of the E-AERI instrument with its internal protective enclosure temporarily removed to show the MR-300 series interferometer housing and electronic modules (photo: Zen Mariani).

normal acquisition mode. Rearranging the placement of the sensors may be required since they failed to detect falling snow several times during the first year of measurements. Temperature, pressure, relative humidity, and sun sensors are also monitored in the enclosure to obtain knowledge of the measurement conditions.

\subsection{Instrument scan sequence}

One measurement cycle includes a zenith-sky measurement as well as calibration measurements of the blackbodies to ensure accurately calibrated zenith-sky spectra. Measurements are independent of sunlight or moonlight and are only interrupted during precipitation events to prevent damage of the optics. The E-AERI is designed to operate on two different repeating scene-mirror schedules in which the downwelling infrared radiation is bracketed by views of the reference blackbodies. Rapid sampling mode is used in order to follow very short-term changes due to variable cloud-cover. In this mode, the E-AERI scene mirror pivots such that the instrument looks at the $\mathrm{HB}, \mathrm{AB}$, and then Sky View (SV) in the following order: HB AB SV SV SV SV SV SV SV $\mathrm{SV}$ AB HB. This is useful for quick measurements of the sky to detect changes in frontal passages. The E-AERI is usually operated in slow sampling mode, following the pattern: HB AB SV AB HB. This method sandwiches each SV measurement between blackbody measurements, improving the calibration of the spectra. The instrument performs two Michelson mirror sweeps (forward and backward) for each spectrum. Co-adding spectra for the blackbodies takes about two minutes, and for the sky view it takes about three minutes, such that 127 co-adds are performed for each blackbody measurement and 248 co-adds are performed for each SV measurement.

\subsection{Blackbodies}

Measurements of the emission from the two blackbodies are used to calibrate the sky-view measurement. The two calibration blackbodies are of identical construction, each consisting of a thermally isolated cavity that is painted with a high-emissivity diffuse black paint. The emissivity of both blackbodies is $>0.999 \pm 0.1 \%$. Each cavity contains a heater, a feedback thermistor and three thermistor sensors. Each blackbody's temperature can be set using the instrument's software. For operation at PEARL, the HB is set at $310 \mathrm{~K}$ and the $\mathrm{AB}$ operates at the outside temperature.

The E-AERI calibration methodology uses a pair of $\mathrm{HB} / \mathrm{AB}$ views bracketing the SV measurements. The blackbody temperatures are fit to a linear function of time to account for changes in the instrument temperature during a calibration sequence. Similarly, a linear interpolation to the SV time is performed for each $\mathrm{HB}$ and $\mathrm{AB}$ measurement. The approach used for radiometric calibration of the E-AERI system is based on that of Revercomb et al. (1988).

\subsection{Data products}

The standard E-AERI data product consists of calibrated downwelling radiance spectra from the two detectors: 4001800 and $1800-3000 \mathrm{~cm}^{-1}$. Combined, these form a continuous spectrum from $400-3000 \mathrm{~cm}^{-1}$. Two data description files and one summary file contain measurement time, instrument parameter metrics, mean radiance, imaginary radiance, corrective offset, responsivity, brightness temperature (sometimes referred to as radiance temperature), blackbody temperature drift, and scene Noise Equivalent Spectral Radiance (NESR) from each detector for each seven-minute sampling interval. The radiance data are automatically processed using instrument-related corrections such as those described in Sect. 2.4 as well as in Knuteson et al. (2004b), resulting in 

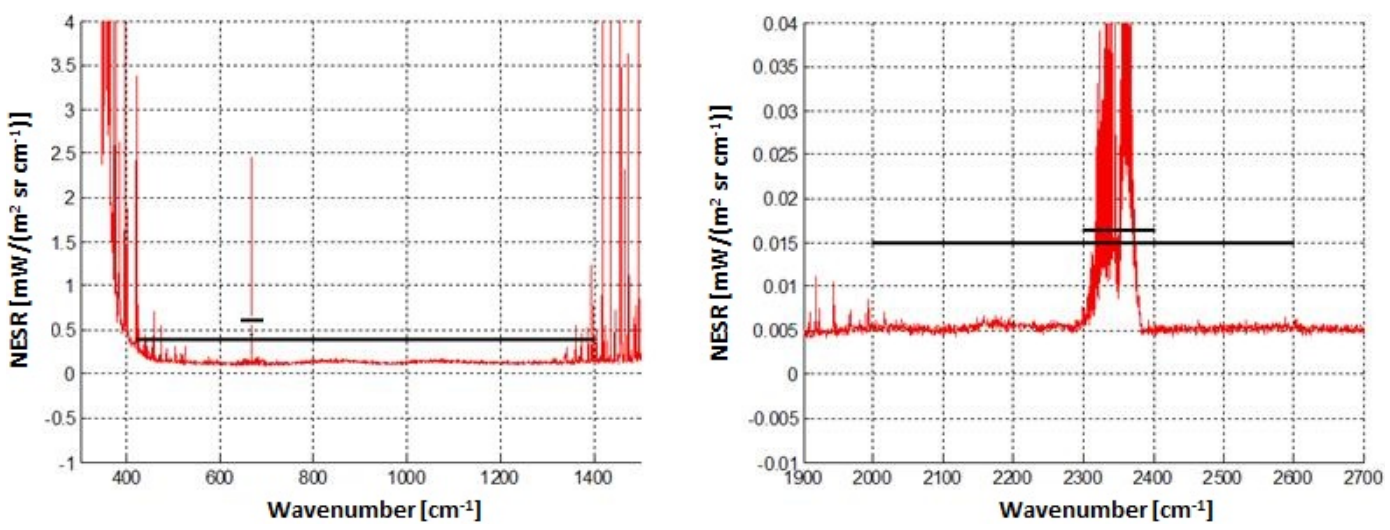

Fig. 2. NESR test for the MCT (left panel) and InSb (right panel) detectors performed in Eureka. The solid black line indicates the specified

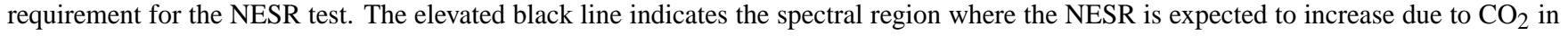
the instrument.

calibrated radiances with a standardized spectral scale in real time.

\subsection{System software architecture}

The E-AERI software system performs all necessary data calibration in real-time. The software also performs a series of quality control checks in real-time and allows unattended operation of the system. The data is accessible via a digital network with an on-board storage capacity of several days. The monitoring Graphical User Interface (GUI) supports interactive use of the instrument and monitors the state of the instrument. Calibrated spectra and some auxiliary parameters are displayed at the end of each scan. Within each window of the monitoring GUI, the radiance, air temperature, Stirling cooler current, and instrument temperature are displayed. Thirty crucial instrument parameters are also monitored using the GUI. Table 1 lists the variables that are used as real-time quality metrics for the E-AERI. If one of these parameters falls outside of a tolerable range, the operators are alerted.

\section{Instrument performance}

\subsection{Performance evaluations}

The performance characteristics of the E-AERI are summarized in Table 2. Items with a "*" indicate performance metrics verified during calibration at UW-SSEC. Measurements of the NESR were performed in Quebec City (before shipping to Eureka) and again at Eureka. The root-mean-square of the variation in the calibrated radiances from $284 \mathrm{spec}-$ tra of the HB determines the NESR. NESR measurements taken at Eureka are shown in Fig. 2. The observed increase in noise at $667 \mathrm{~cm}^{-1}$ and from $2300-2400 \mathrm{~cm}^{-1}$ is due to $\mathrm{CO}_{2}$ absorption inside the instrument, which reduces responsivity. For both the long wavelength (LW; MCT) and short wavelength ( $\mathrm{SW}$; InSb) bands, the NESR is well below the specified requirement; about one-half and one-third of the specification for the LW and SW, respectively. One exception is in the region around $400 \mathrm{~cm}^{-1}$; due to the higher NESR at this edge of the LW band, a new detector will be installed in fall 2011.

The E-AERI was sent to UW-SSEC for calibration and performance evaluation in September 2008. A four-body test was performed using the $\mathrm{AB}, \mathrm{HB}$ (set to $330 \mathrm{~K}$ for these tests), an intermediate blackbody (temperature between $\mathrm{AB}$ and $\mathrm{HB}$, around $318 \mathrm{~K}$ ), and an Ice-Blackbody (IB) at $273 \mathrm{~K}$. The intermediate body and IB are used as external reference sources to verify blackbody temperature knowledge. These external reference sources are calibrated using the same $\mathrm{Na}-$ tional Institute of Standards and Technology traceable approach as used for the other blackbodies. During the test period, the scene mirror views each blackbody to measure the blackbody temperatures over several hours to ensure stability and reduce the noise level.

Calibration verification test results are shown in Fig. 3 for the intermediate body and IB. Water vapour has strong absorption between 1450 and $1800 \mathrm{~cm}^{-1}$ and $\mathrm{CO}_{2}$ has strong absorption around 667 and $2380 \mathrm{~cm}^{-1}$, resulting in the observed discrepancies in these regions. The IB measurement has an offset of $0.2 \mathrm{~K}$; this is comparable to the error of $\pm 0.2 \mathrm{~K}$ for other AERI systems (Knuteson et al., 2004a). This error can be due to incorrect placement of the ice-body (too far away or not exactly centred).

A side-by-side comparison with two UW AERI systems, the AERI-07 (with an extended-range detector) and the AERI-Bago (AERI-03), was performed. These instruments have been employed in numerous measurement campaigns and are considered reliable benchmarks for measurement inter-comparison purposes (Knuteson et al., 2004a). Results from these comparisons indicate that agreement between the E-AERI and the other two instruments is comparable to the agreement between the AERI-07 and AERI-Bago, as shown 
Table 1. Parameter metrics used when monitoring the status of the E-AERI. The normal operating range customized for operation at Eureka lies between the limits shown.

\begin{tabular}{|c|c|c|}
\hline Parameter & Normal Operating Limits & Description \\
\hline AB Temperature & $243.15,313.15 \mathrm{~K}$ & $\begin{array}{l}\text { Temperature range of the given instrument } \\
\text { components }\end{array}$ \\
\hline HB Temperature & $263.15,353.15 \mathrm{~K}$ & \\
\hline Outside Temperature & $233.15,323.15 \mathrm{~K}$ & \\
\hline Rack Ambient Temperature & $277.15,319.15 \mathrm{~K}$ & \\
\hline Rain Intensity & $2.5,3.2 \mathrm{~V}$ & $\begin{array}{l}\text { Measured rain intensity range that triggers the hatch } \\
\text { to close }\end{array}$ \\
\hline AB Maximum Temperature Difference & $0.1 \mathrm{~K}$ & $\begin{array}{l}\text { Maximum allowed temperature difference between } \\
\text { the three temperature sensors inside each blackbody }\end{array}$ \\
\hline HB Maximum Temperature Difference & $0.7 \mathrm{~K}$ & \\
\hline B. B. Support Structure Temperature & $233.15,323.15 \mathrm{~K}$ & $\begin{array}{l}\text { Temperature range of the given instrument } \\
\text { components }\end{array}$ \\
\hline Air Temperature near Blackbodies & $233.15,343.15 \mathrm{~K}$ & \\
\hline SCE Temperature & $273.15,333.15 \mathrm{~K}$ & \\
\hline Air Humidity & $1,99 \%$ & Air humidity range \\
\hline HB Stability & $-0.5,0.5 \mathrm{~K}$ & HB temperature variability during a scan \\
\hline Mirror Motor Temperature & $233.15,363.15 \mathrm{~K}$ & Temperature range of the scene mirror motor \\
\hline Atmospheric Pressure & $750.0,1040.0 \mathrm{~Pa}$ & Atmospheric pressure range \\
\hline 336 Kelvin (Reference) & $2426.96,2433.04 \Omega$ & $\begin{array}{l}\text { Measured resistance range for the reference } \\
\text { temperature resistors (used to calibrate blackbody } \\
\text { temperatures) }\end{array}$ \\
\hline 293 Kelvin (Reference) & $10480.04,10493.96 \Omega$ & \\
\hline 249 Kelvin (Reference) & $97232,98272 \Omega$ & \\
\hline Motor Driver Temperature & $273.15,323.15 \mathrm{~K}$ & $\begin{array}{l}\text { Temperature range of the given instrument } \\
\text { components }\end{array}$ \\
\hline Interferometer Window Temperature & $293.596,324.924 \mathrm{~K}$ & \\
\hline Encoder Scene Confirm & $-5,50.01^{\circ}$ & $\begin{array}{l}\text { Confirmation of scene mirror position (range: min, } \\
\text { max; and precision) }\end{array}$ \\
\hline LW HB NEN & $0,1 \mathrm{~mW} /\left(\mathrm{m}^{2} \mathrm{srcm}^{-1}\right)$ & $\begin{array}{l}\text { Noise estimation (NEN) for the long- and short- } \\
\text { wave by use of the } \mathrm{HB}\end{array}$ \\
\hline SW HB NEN & $0,0.1 \mathrm{~mW} /\left(\mathrm{m}^{2} \mathrm{srcm}^{-1}\right)$ & \\
\hline Air Temperature near Interferometer & $293.87,322.09 \mathrm{~K}$ & $\begin{array}{l}\text { Temperature range of the air near the MR- } 300 \\
\text { interferometer }\end{array}$ \\
\hline LW Responsivity & $0.0104,5$ Counts $/ \mathrm{mW} /\left(\mathrm{m}^{2} \mathrm{srcm}^{-1}\right)$ & $\begin{array}{l}\text { Estimated long- and short-wave responsivity of the } \\
\text { system during a scan }\end{array}$ \\
\hline SW Responsivity & $0.0112,20$ Counts $/ \mathrm{mW} /\left(\mathrm{m}^{2} \mathrm{sr} \mathrm{cm}^{-1}\right)$ & \\
\hline Cooler Compressor Temperature & $290.398,350.202 \mathrm{~K}$ & Range of the cooler compressor temperature \\
\hline Cooler Current & $0.03,0.086 \mathrm{Amp}$ & Range of current used by the cooler \\
\hline Cooler Expander Temperature & $285.0,368.4 \mathrm{~K}$ & Temperature range of the hot end of the cooler \\
\hline Detector Temperature & $61.3,70.4 \mathrm{~K}$ & Range of the detector's temperature \\
\hline
\end{tabular}


Table 2. E-AERI instrument performance.

\begin{tabular}{|c|c|}
\hline Item & Performance \\
\hline General System Elements & $\begin{array}{l}\text { - ABB Bomem MR-300 Michelson interferometer with PC computer interface } \\
\text { - Full-aperture temperature-controlled calibration reference sources } \\
\text { - Automated system for providing sequential views of the sky (zenith) and two blackbodies } \\
\text { (one at ambient temperature, one at } 37^{\circ} \mathrm{C} \text { ) for radiometric calibration } \\
\text { - Environmental Monitoring System, for blackbody temperature data } \\
\text { - Computer and Data Handling System, for sequencing all E-AERI operations and data handling, } \\
\text { including acquisition, processing, display, and networking }\end{array}$ \\
\hline Spectral range* & $400-3000 \mathrm{~cm}^{-1}(3.3-25 \mu \mathrm{m})$ \\
\hline Spectral resolution* & $1.0 \mathrm{~cm}^{-1}$, unapodized maximum optical path difference (OPD) of $1 \mathrm{~cm}$ \\
\hline Spatial and angular FOV* & $46 \pm 1 \mathrm{mrad}$ full angle \\
\hline $\begin{array}{l}\text { Radiometric calibration absolute } \\
\text { accuracy* }\end{array}$ & $<1 \%$ of ambient blackbody radiance \\
\hline Reproducibility* & $<0.2 \%$ of ambient blackbody radiance \\
\hline Blackbody cavity characterization* & $\begin{array}{l}\text { - Temperature Knowledge: } \pm 0.1^{\circ} \mathrm{C} \text { of absolute temperature } \\
\text { - Emissivity knowledge: better than } \pm 0.1 \% \\
\text { - Temperature stability: better than } 0.05^{\circ} \mathrm{C} \text { over viewing period }(\gg 120 \mathrm{~s})\end{array}$ \\
\hline Nonlinearity knowledge* & Better than $0.1 \%$ \\
\hline Polarization* & Scene mirror imposes $<0.1 \%$ polarization on incident unpolarized radiation \\
\hline Wavelength calibration* & Channel wavenumber knowledge: better than $0.01 \mathrm{~cm}^{-1}$ \\
\hline $\begin{array}{l}\text { Noise (RMS for 2-min blackbody } \\
\text { view)* }\end{array}$ & $\begin{array}{l}<0.4 \mathrm{~mW}\left(\mathrm{~m}^{2} \mathrm{srcm}^{-1}\right)^{-1} \text { for } 420-1400 \mathrm{~cm}^{-1} \text { (except } 667 \mathrm{~cm}^{-1} \text {, where } \mathrm{CO}_{2} \text { in the instrument reduces } \\
\text { responsivity) } \\
<0.015 \mathrm{~mW}\left(\mathrm{~m}^{2} \mathrm{srcm}^{-1}\right)^{-1} \text { for } 2000-2600 \mathrm{~cm}^{-1} \text { (except } 2300-2400 \mathrm{~cm}^{-1} \text {, where } \mathrm{CO}_{2} \text { in the } \\
\text { instrument reduces responsivity) }\end{array}$ \\
\hline Temporal sampling & $\begin{array}{l}\text { Repeat cycle: } \approx 7 \text { min } \\
\text { Interferometer scan period: }<2 \mathrm{~s}\end{array}$ \\
\hline Detectors & $\begin{array}{l}\text { Two detectors are mounted in sandwich configuration covering two spectral regions: } \\
\text { Channel one }\left(400-1800 \mathrm{~cm}^{-1}\right) \text { : extended-range photoconductive mercury cadmium telluride (MCT) } \\
\text { Channel two }\left(1800-3000 \mathrm{~cm}^{-1}\right) \text { : photovoltaic indium antimonide (InSb) }\end{array}$ \\
\hline Beamsplitter & Potassium bromide $(\mathrm{KBr})$ \\
\hline Operational requirement & $\begin{array}{l}\text { Automatic control system hardware contains these features: } \\
\text { - Scheduled sequencing of the following operations: } \\
\text { - Scene switching between sky and blackbody views } \\
\text { - Interferometer and housekeeping data acquisition and transfer } \\
\text { - Capability of remotely changing the operation listed above } \\
\text { - 24-h continuous operations with data output at 7-min intervals } \\
\text { - Linear stirling-cycle cryo-cooler keeps detectors cooled down below } 70 \mathrm{~K} \\
\text { - Real-time display with flags for out-of-limit conditions }\end{array}$ \\
\hline Operating environment & $\begin{array}{l}\text { Operating temperature: } \\
\text { - Spectroradiometer (back-end) enclosure: }-30^{\circ} \text { to }+40^{\circ} \mathrm{C} \\
\text { - Input and calibration (front-end) enclosure: }-70^{\circ} \text { to }+40^{\circ} \mathrm{C}\end{array}$ \\
\hline Data products & $\begin{array}{l}\text { Primary (required for scientific use): } \\
\text { - Calibrated spectra } \\
\text { - Standard deviation for blackbody and sky views } \\
\text { - Calibration coefficient and blackbody temperature } \\
\text { - Secondary (auxiliary information for real-time monitoring and quality control): } \\
\text { - Ambient air temperature } \\
\text { - Ambient pressure } \\
\text { - Ambient humidity } \\
\text { - Instrument housekeeping data }\end{array}$ \\
\hline
\end{tabular}

Items with a "**" indicate performance metrics verified during calibration at UW-SSEC. 

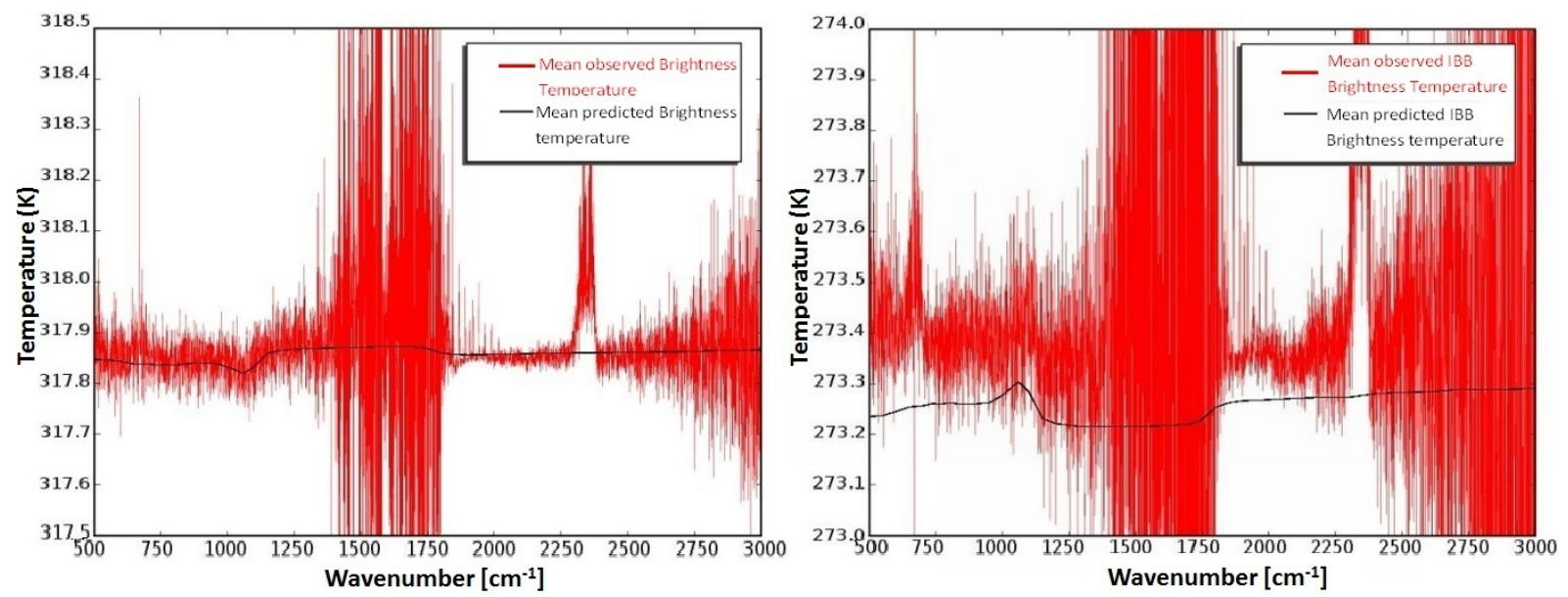

Fig. 3. Laboratory radiometric calibration verification "four-body" test results conducted at UW-SSEC on 27 September 2008 before deployment to Eureka. Left panel: intermediate black-body brightness temperature spectrum. Right panel: IB brightness temperature spectrum. The measured spectrum (red) is the temporal-averaged calibrated radiance converted to equivalent blackbody brightness temperature. Note the $\mathrm{y}$-axis range in both panels is $1 \mathrm{~K}$. The black line indicates the predicted blackbody temperature.
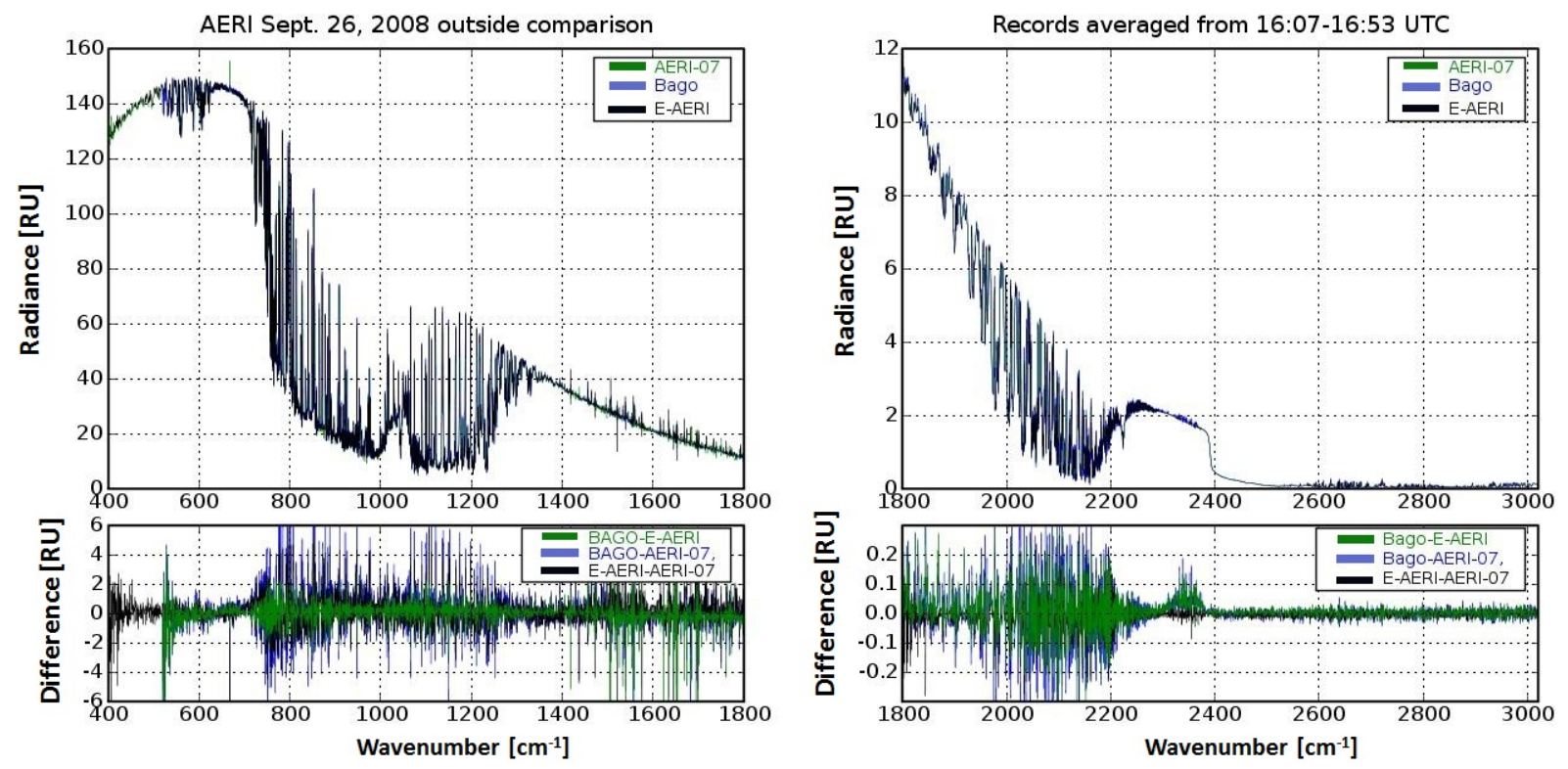

Fig. 4. Radiance measurements during two outside side-by-side tests performed at UW. Top panels display measured radiance $\left(\mathrm{RU}=\mathrm{mW} /\left(\mathrm{m}^{2} \mathrm{sr} \mathrm{cm}^{-1}\right)\right)$ with residuals in the bottom panels.

in Fig. 4, verifying the accuracy of the E-AERI radiances (UW-SSEC, 2008).

Three field-of-view tests were performed on the zenithsky, $\mathrm{HB}$, and $\mathrm{AB}$ views and confirmed proper optical alignment of the source and reference blackbody cavities. Wavenumber calibration was performed by finding an effective laser wavenumber value for the HeNe laser that provides the best spectral match for regions of regular spectral lines. The wavenumber knowledge was found to be $0.0018 \mathrm{~cm}^{-1}$, which is better than the $0.01 \mathrm{~cm}^{-1}$ requirement. A spectral line stability test was performed by tracking any movement in the $1918 \mathrm{~cm}^{-1}$ water line during the ambient blackbody measurements for twenty hours. The wavenumber stability also meets the requirement of $<10 \mathrm{ppm}$.

\subsection{Side-by-side comparisons with the P-AERI at sea-level}

Prior to its installation at the PEARL Ridge Lab, the EAERI was operated side-by-side with the P-AERI at OPAL for several days. The P-AERI has been extensively characterized (Walden et al., 2005; Rowe et al., 2008) and the 
data at Eureka have been quality controlled (Rowe et al., 2011a,b). With exception of the E-AERI's extended range $\left(400-550 \mathrm{~cm}^{-1}\right)$, the P-AERI has similar specifications to the E-AERI and a measurement period that overlaps the EAERI's, providing an opportunity for comparing the two instruments and evaluating the E-AERI spectra. Coincident E-AERI and P-AERI radiances recorded on 20 October 2008 are shown in Fig. 5 for the P-AERI spectral range of 500 to $3000 \mathrm{~cm}^{-1}$. Strong trace gas absorption can also cause large errors in calibrated sky spectra; these spectra are corrected as part of the post-processing as discussed in detail by Rowe et al. (2011b). The radiances agree within $\pm 1 \mathrm{~mW} /\left(\mathrm{m}^{2} \mathrm{srcm}^{-1}\right)$ for the MCT detector and $\pm 0.2 \mathrm{~mW} /\left(\mathrm{m}^{2} \mathrm{srcm}^{-1}\right)$ for the InSb detector with the exception of the $1450-1800 \mathrm{~cm}^{-1}$ spectral region, due to humidity inside the E-AERI. After ten days in the dry Arctic air, the water vapour inside the E-AERI evaporated and such discrepancies ceased to exist. These results are comparable to the AERI-07 and AERI-03 comparisons.

\section{A first look at PEARL E-AERI spectra}

\subsection{Impact of clouds on the radiation budget}

The ability of AERI systems to detect the presence of clouds and provide information about cloud properties has been well demonstrated (e.g., Collard et al., 1995; DeSlover et al., 1999; Shaw et al., 2005; Turner, 2005). Figure 6a shows EAERI measurements made on 16 April 2009 at 00:08 UTC (Universal Time Coordinated) and 17:57 UTC. The MMCR indicates that on 16 April, early-morning clear skies were followed by a thick cloud layer above Eureka for the remainder of the afternoon and evening (Fig. 7). The top panel of Fig. 7 shows the measured equivalent radar reflectivity (dBZ), the middle panel shows the measured Doppler velocity $\left(\mathrm{m} \mathrm{s}^{-1}\right)$, and the bottom panel shows the measured spectral width $\left(\mathrm{m} \mathrm{s}^{-1}\right)$. This figure shows slowly descending cirrus clouds. The cloud is mostly ice until around 09:00 UTC; then the spectral width increases (as indicated by the appearance of green shading), which may be due to the presence of liquid water. The E-AERI radiance increases after 04:00 UTC in the $400-600 \mathrm{~cm}^{-1}$ and $750-1400 \mathrm{~cm}^{-1}$ regions due to emission by cloud particles, correlating with the MMCR's detection of a low-altitude, relatively thick $(\sim 2 \mathrm{~km})$ cirrus cloud that first appeared above Eureka at 04:00 UTC. Figure $6 \mathrm{~b}$ displays the brightness temperature measured by the E-AERI throughout the day. Periods of increased brightness temperature correlate with increased cloud cover above Eureka. The averaged radiance over 750$1200 \mathrm{~cm}^{-1}$ increases from 4.4 to $21.6 \mathrm{~mW} /\left(\mathrm{m}^{2} \mathrm{sr} \mathrm{cm}^{-1}\right)$ and the brightness temperature increases $44 \%$.

Measurements made by an AERI instrument at the Southern Great Plains Cloud and Radiation Testbed show considerably smaller increases (typically an increase from $\sim 10$ to

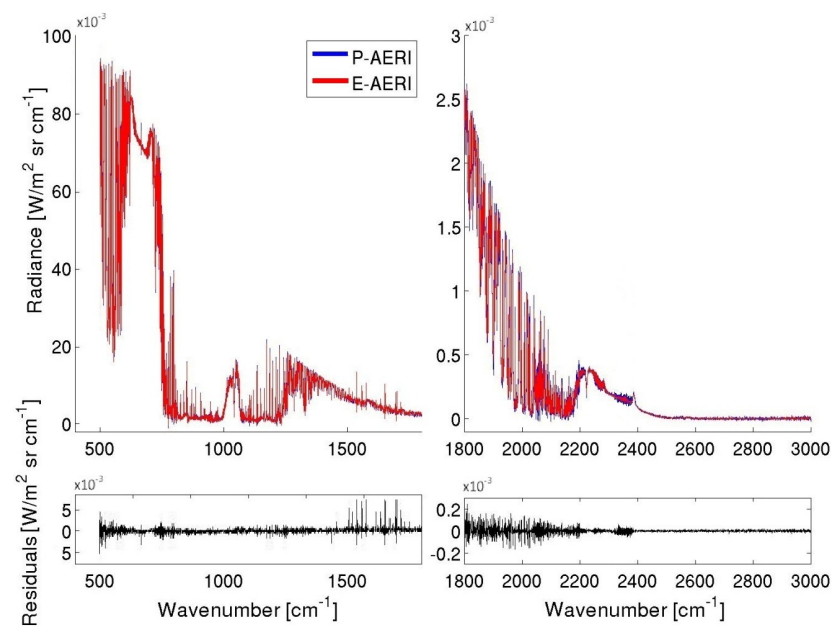

Fig. 5. Side-by-side comparisons between the E-AERI (red) and P-AERI (blue) instruments within the P-AERI spectral range on 20 October 2008 . Top panels display measured radiance with residuals in the bottom panels.

$\sim 30 \mathrm{~mW} /\left(\mathrm{m}^{2} \mathrm{srcm}^{-1}\right)$ averaged over $\left.750-1200 \mathrm{~cm}^{-1}\right)$ in the presence of similarly thick clouds (Turner et al., 2000), while previous measurements in the high Arctic taken at the Surface Heat Budget of the Arctic Ocean (SHEBA) show increases similar or larger to those made by the E-AERI in Eureka (typically $>40 \%$ increase in brightness temperature averaged over $750-1200 \mathrm{~cm}^{-1}$ ) (Turner, 2005). Thus the impact of clouds on the radiation budget is greater in the Arctic than in other more humid regions due to the extremely cold and dry Arctic air and hence to the main atmospheric window being more transparent. This coincides with model results suggesting that the impact of clouds on the radiative budget is most pronounced for the Arctic (Vavrus, 2004). Such large increases in radiance and brightness temperatures in these spectral regions provide a proxy for cloud detection and enable analysis of cloud optical depth, phase, and particle size (Turner, 2005). Cloud detection is crucial in the post-processing of E-AERI data since temperature and trace gas retrievals using SFIT2 are significantly more difficult in cloudy scenes.

\subsection{Investigation of the lower $610 \mathrm{~m}$ using the P-AERI}

E-AERI measurements were recorded at the PEARL Ridge Lab from October 2008 to September 2009. Comparisons between coincident E-AERI (at $610 \mathrm{~m}$ ) and P-AERI (at $10 \mathrm{~m}$ ) measurements of radiance from October 2008-April 2009 are shown in Fig. 8. Radiances were averaged on an hourly basis and used to calculate radiance differences. Each column of Fig. 8 corresponds to a single coincident hourlyaveraged P-AERI - E-AERI spectrum. Typical temperature profiles for the high Arctic frequently exhibit temperature inversions (due to the extremely cold surface) for the first two 

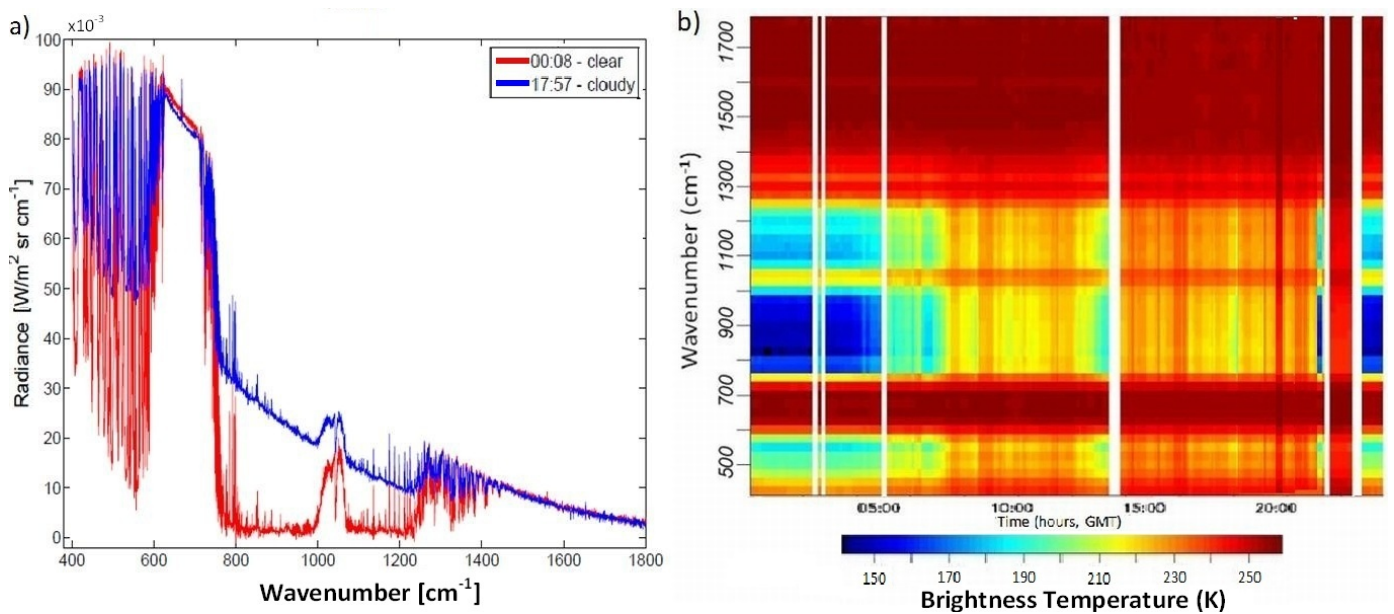

Fig. 6. (a) E-AERI measurements of radiance on 16 April 2009 at 00:08 UTC (red) and 17:57 UTC (blue). (b) Brightness temperatures measured throughout 16 April 2009. White spaces correspond to periods of no measurement (instrument reboot, precipitation). Only the longwave spectral region (up to $1800 \mathrm{~cm}^{-1}$ ) is shown for clarity.

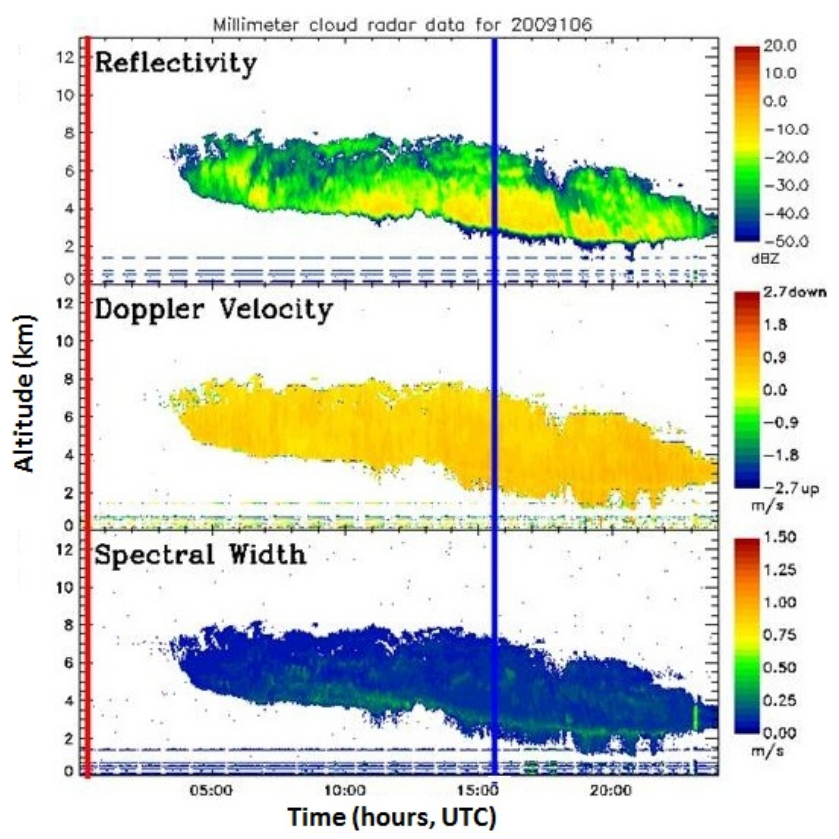

Fig. 7. MMCR reflectivity, Doppler velocity, and spectral width plots for 16 April 2009. Red and blue vertical bars correspond to the time of E-AERI measurements, at 00:08 UTC and 17:57 UTC, respectively, shown in Fig. 6a.

kilometers above the surface; thus temperatures at the Ridge Lab are typically $\sim 20 \mathrm{~K}$ warmer than at 0 PAL depending on the time of year. This is reflected in the $600-800 \mathrm{~cm}^{-1} \mathrm{CO}_{2}$ band (which is where the largest differences in Fig. 8 occur), corresponding to warmer temperatures at the Ridge Lab and a smaller $\mathrm{CO}_{2}$ column (due to the $600 \mathrm{~m}$ elevation difference) resulting in greater E-AERI radiances. Other periods with large differences between the instruments correspond to the occurrence of ice crystals, high aerosol concentrations, fog or low cloud cover. For instance, the large radiance differences (red bands) in February occur on days for which low-level clouds were present above Eureka. For the low-level clouds that exist below $610 \mathrm{~m}$, only the P-AERI can measure the increased emission from the cloud particles; hence the radiance difference increases for such days.

\subsection{Comparisons with simulated radiances}

Clear-sky comparisons between the E-AERI and P-AERI measurements at 00:08 UTC on 4 April 2009, are shown in Fig. 9a, with the residuals (P-AERI - E-AERI) in Fig. 9d. Large negative residuals in the $600-800 \mathrm{~cm}^{-1}$ and $1600-$ $1800 \mathrm{~cm}^{-1}$ spectral regions correspond to differences $>14 \%$ and $>33 \%$, respectively. Such differences are expected due to the large temperature and humidity difference at the two sites and the absorption by $\mathrm{CO}_{2}$ and $\mathrm{H}_{2} \mathrm{O}$, emphasizing the dependence of the radiative budget on the atmospheric temperature and relative humidity profile. Positive residuals typically occur in more transparent spectral regions where $\mathrm{CO}_{2}$ absorption does not exist; they are positive due to the additional $600 \mathrm{~m}$ of atmospheric emission measured by the PAERI. The measured radiance differences provide insight into the spectral regions that experience increasing or decreasing downwelling radiance at different altitudes.

The 4 April 2009 radiances were simulated using a Fast Line-By-Line Radiative Transfer Model (FLBLRTM) for an altitude of $10 \mathrm{~m}$ (P-AERI) and $610 \mathrm{~m}$ (E-AERI). The FLBLRTM is a faster version of a standard Line-By-Line Radiative Transfer Model (LBLRTM), as developed in Clough et al. (2005). This is achieved by replacing the computationally expensive section of the LBLRTM code that calculates 


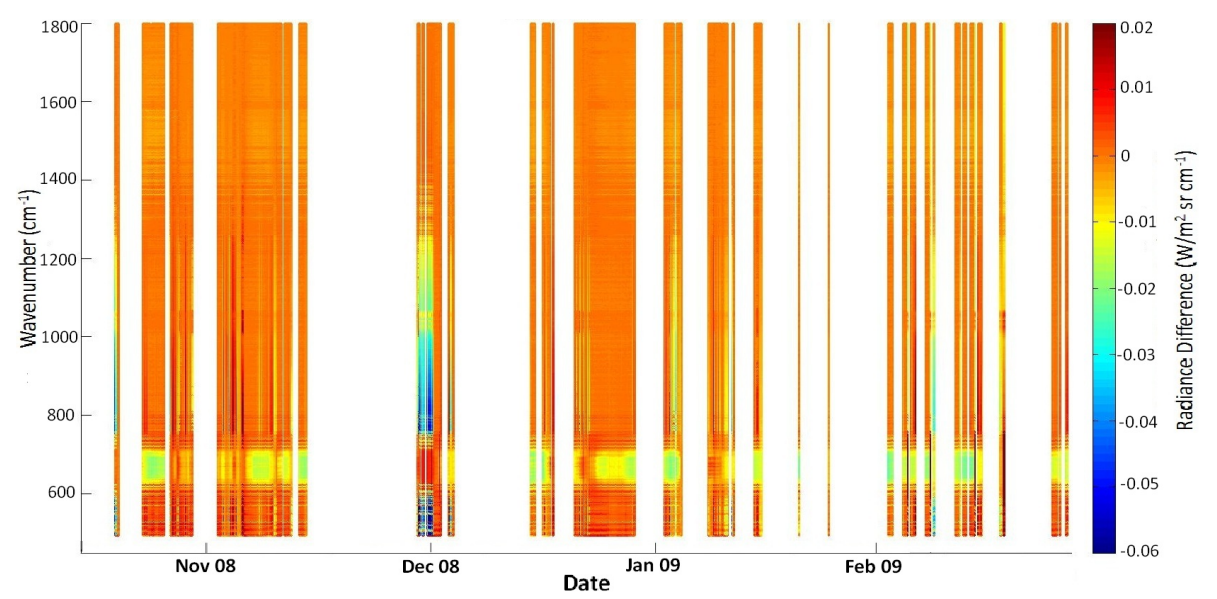

Fig. 8. Hourly-averaged coincident radiance difference measurements (P-AERI - E-AERI) from 22 October 2008 to 5 April 2009 . Only the longwave radiances are shown for clarity. White spaces correspond to periods with no measurement overlap due to precipitation or instrument maintenance.

absorption coefficients directly from a spectral database with absorption coefficient lookup tables set on a wavenumber, pressure, and temperature grid. Although the absorption coefficient has an absorber amount dependency, it is generally insignificant for atmospheric cases (Turner, 1995). Water vapour is an exception and is treated differently in that two tables are required to represent it instead of one as with other absorbers. In addition to speeding up the calculation, the use of tables also reduces the amount of code and hence enables the code to be relatively easy to tailor to a specific problem.

For this work, absorption coefficient tables for $\mathrm{H}_{2} \mathrm{O}, \mathrm{CO}_{2}$, $\mathrm{O}_{3}, \mathrm{~N}_{2} \mathrm{O}, \mathrm{CO}, \mathrm{CH}_{4}, \mathrm{O}_{2}$ and $\mathrm{N}_{2}$ were created for the spectral region from 400 to $3000 \mathrm{~cm}^{-1}$ on a grid interval of $0.005 \mathrm{~cm}^{-1}$. The spectral line data are taken from HITRAN 2008 (Rothman et al., 2009). The $\mathrm{H}_{2} \mathrm{O}$ continuum is accounted for by the CKD2.4 continuum model (Clough et al., 1989) and in all cases the Voigt line shape is assumed. The CKD2.4 continuum is compatible with HITRAN86; the addition of new $\mathrm{H}_{2} \mathrm{O}$ spectral lines in updated versions of HITRAN are generally very weak and do not affect the end result, particularly for a lower-resolution instrument.

The radiances are computed for clear skies with no aerosols. Temperature, pressure, and relative humidity data from Vaisala radiosondes launched near 0 PAL were interpolated to 00:08 UTC on 4 April and included in the simulation. Results from the model simulations are shown in Fig. $9 \mathrm{~b}$ and agree with E- and P-AERI radiances within $\pm 20 \mathrm{~mW} /\left(\mathrm{m}^{2} \mathrm{sr} \mathrm{cm}^{-1}\right)$. The simulated E-AERI spectrum in the $1600-1800 \mathrm{~cm}^{-1}$ region is significantly smoother than the measured E-AERI spectrum. Model simulations at altitudes varying from the surface to $3 \mathrm{~km}$ indicate emission and absorption features in this spectral region become quickly saturated as altitude increases. Model simulations also indicate that the simulated radiances are very sensitive to changes in temperature and $\mathrm{H}_{2} \mathrm{O}$ for the lowest $3 \mathrm{~km}$ of the atmosphere. Radiosonde $\mathrm{H}_{2} \mathrm{O}$ profiles have lower accuracy $(10-20 \%)$ at the low humidities encountered in the Arctic, causing large biases in the radiosonde profile (Schneider et al., 2010). When the $\mathrm{H}_{2} \mathrm{O}$ profile is decreased by $20 \%$ in the model simulation, the emission and absorption features are no longer saturated and the spectrum in this spectral region is less smooth. The radiosonde temperature profile used to produce the simulated radiances also has small errors of $<2 \mathrm{~K}$. Changing the temperature profile by $\pm 1, \pm 2$, and $\pm 5 \mathrm{~K}$ in the model simulations results in a shift in the baseline radiance. Hence biases in the radiosonde temperature and $\mathrm{H}_{2} \mathrm{O}$ profiles used in the simulation cause the simulated radiances to saturate and deviate from the true state, resulting in the observed discrepancy.

Differences between the measured radiances (Fig. 9a) and simulated radiances (Fig. 9b) are shown in Fig. 9c and have good agreement with the exception of the wings of the 600$800 \mathrm{~cm}^{-1} \mathrm{CO}_{2}$ band. Differences between the measured PAERI - E-AERI radiance differences (Fig. 9d) and the corresponding simulated radiance differences (Fig. 9e) are shown in Fig. $9 \mathrm{f}$ and indicate agreement for the majority of the spectrum with slightly larger differences around the 600$800 \mathrm{~cm}^{-1} \mathrm{CO}_{2}$ band, further indicating small errors in the radiosonde temperature profile. The differences between the simulated and measured spectra indicate the model's reliance on accurate radiosonde temperature profiles in order to accurately describe Arctic radiances. Large errors in the 400$600 \mathrm{~cm}^{-1}$ (>29\%) region also indicate the model's reliance on accurate relative humidity profiles. 
a)

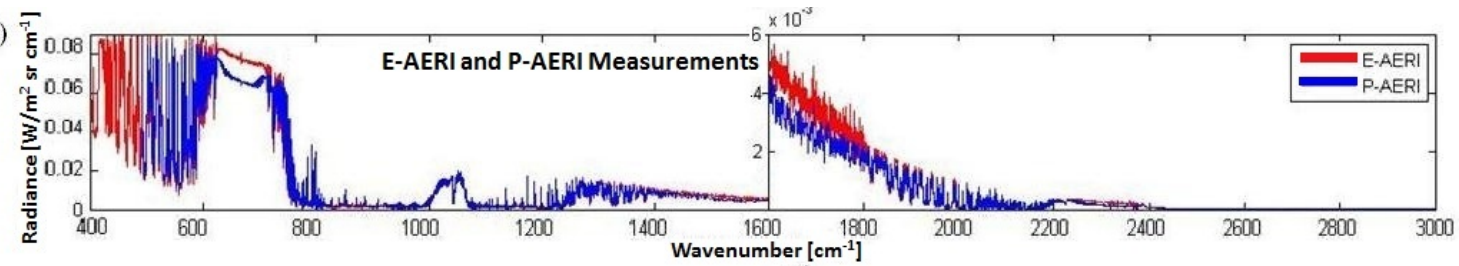

(1)
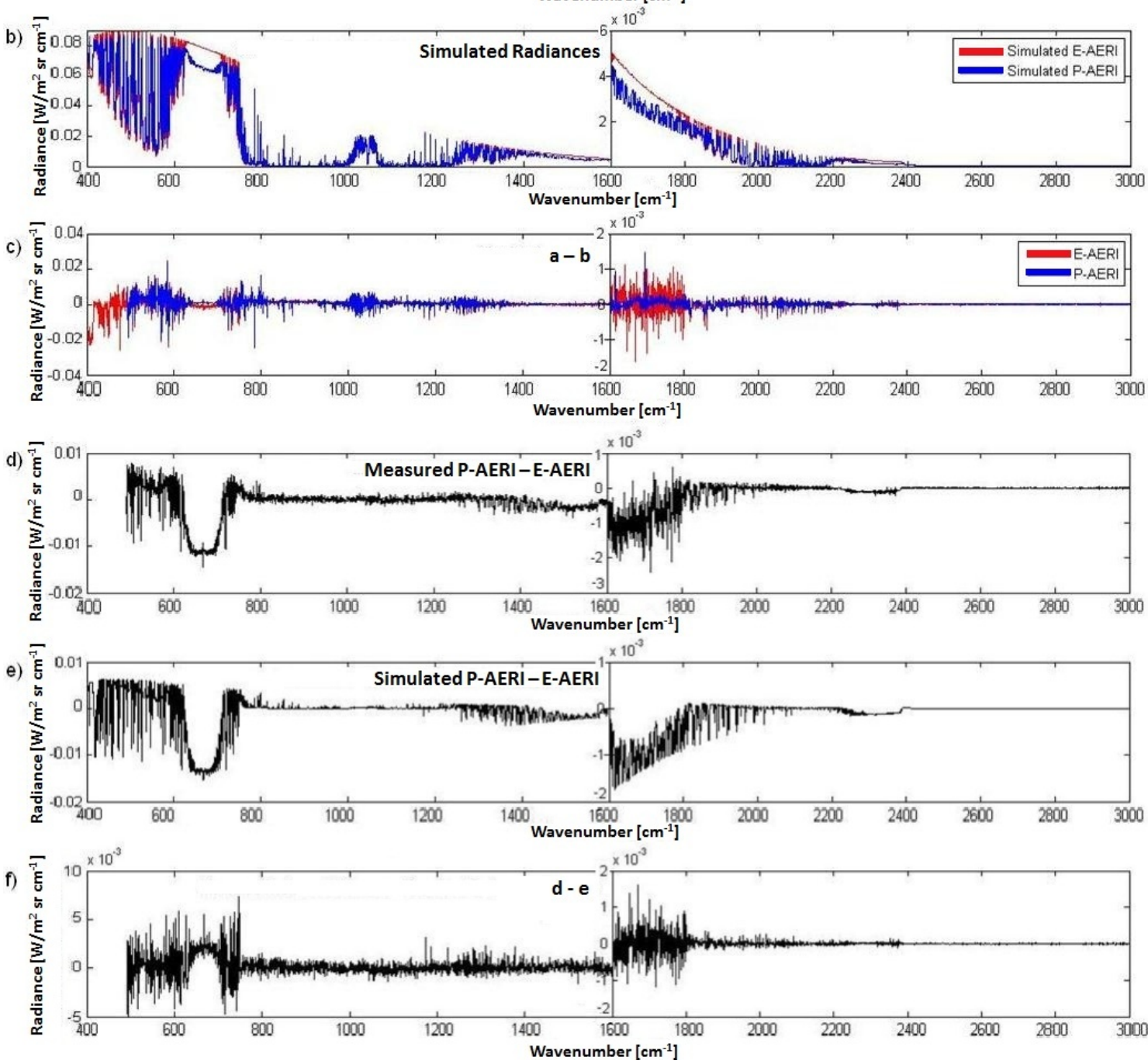

Fig. 9. (a) E-AERI (red) and P-AERI (blue) measured radiances at 00:08 (UTC) on 4 April 2009 with (b) simulated spectra shown below. (c) Differences between the measured and simulated spectra for each instrument (a-b). (d) Measured residuals (P-AERI - E-AERI) with (e) simulated residuals shown below. (f) Differences between the measured and simulated radiance differences (d-e).

\subsection{Radiative impact of an ice crystal cloud within the first $610 \mathrm{~m}$}

A low-level ice crystal cloud was present on the last measurement overlap day shown in Fig. 8 (5 April 2009), as reported throughout the day by a meteorological technician at the Eureka weather station. A 10-min interval (20:30-20:40 UTC) was selected from this day since the ice crystals were concentrated below $610 \mathrm{~m}$ at this time. This provides a unique opportunity to assess the impact of ice crystals on the radiative budget at two altitudes; one above the ice crystals (E-AERI) and one below (P-AERI). Figure 10 shows backscatter crosssection and depolarization ratios measured by the AHSRL, which was deployed at Eureka in August 2005 and was operated throughout the period of interest. The circular particulate depolarization ratio was $>20 \%$ below $\sim 700$ m (indicating ice crystals), and the backscatter cross-section above the ice crystal cloud was $<10^{-6} \mathrm{~m}^{-1} \mathrm{sr}^{-1}$ (indicating that liquid water clouds or precipitation were not associated with the ice crystal event). Both of these conditions pass the criteria used to screen for ice crystals in Lesins et al. (2009). 

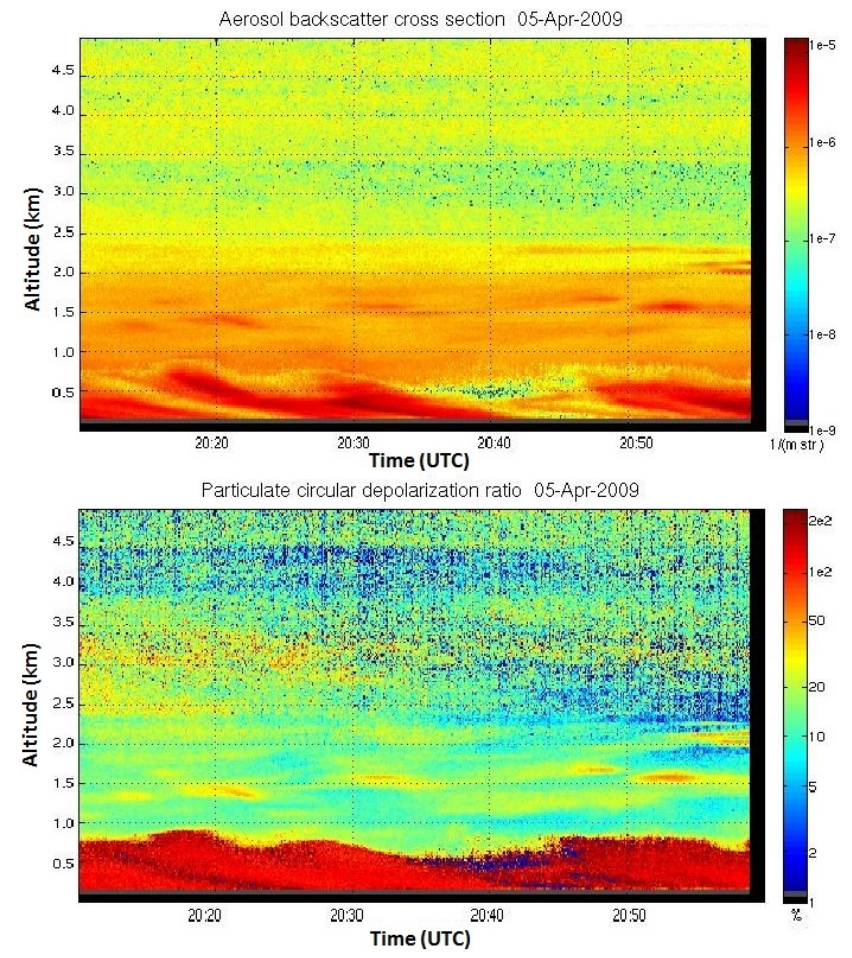

Fig. 10. AHSRL measurements of backscatter cross section (top panel) and particulate circular depolarization ratio (bottom panel) between 20:10 and 21:00 UTC on 5 April 2009. From 20:30-20:40, the top of the ice crystal cloud was $\sim 610 \mathrm{~m}$, where the E-AERI is located.

Ice crystal radiances were compared to clear-sky radiances measured the day before (4 April 2009) at 00:08-00:18 UTC, as shown in Fig. 11. The temperature difference between the two measurement times (4-5 April) was $-4 \mathrm{~K}$ at $0 \mathrm{PAL}$ and $+3 \mathrm{~K}$ at the PEARL Ridge Lab, accounting for differences in the $600-800 \mathrm{~cm}^{-1} \mathrm{CO}_{2}$ band (radiation emitted by ice crystals on 5 April also contribute to differences in this region, but to a lesser degree). This temperature difference is shown in the radiosonde temperature profiles for 4 and 5 April in Fig. 12 (left panel). Radiosonde relative humidity profiles are also shown in Fig. 12 (right panel). The temperature at the top of the ice crystal cloud $(\sim 610 \mathrm{~m})$ was $-26.0^{\circ} \mathrm{C}$ and the temperature at the surface $(10 \mathrm{~m})$ was $-33.9^{\circ} \mathrm{C}$. Brightness temperatures at the top of the ice crystal cloud are greater than at the bottom due to the strong temperature inversion illustrated in Fig. 12 (left panel). Radiance measurements made during these two 10-min time intervals were averaged, and both instruments' differences (ice-clear) are shown in the bottom two panels of Fig. 11. The P-AERI measured the largest increases in radiance in the cloud sensitive 'atmospheric window' $\left(750-1000 \mathrm{~cm}^{-1}\right)$ since it was located below the ice crystal cloud and received emission from the ice particles. For instance, the largest ice crystal-clear sky difference increase in this spectral region was $104 \%$ for the P-AERI and only $6 \%$ for the E-AERI.
Longwave downwelling radiances during the 5 April case were converted to longwave downwelling all-sky irradiance based on the method of Cox et al. (2011). This method models the portion of the infrared spectrum not measured by the AERI and accounts for the radiance anisotropy associated with the viewing zenith angle. The model requires vertical profiles of temperature and humidity, which were obtained by interpolation between the two radiosondes that bracket the times of the AERI measurements. This is important to avoid inclusion of irradiance contributions in spectral regions (such as $600-800 \mathrm{~cm}^{-1}$ ) associated with the temperature structure and not the cloud. For the atmospheric profile associated with the E-AERI, only the radiosonde measurements above $610 \mathrm{~m}$ were used and the $610-\mathrm{m}$ temperature was set to the brightness temperature near the centre of the $600-800 \mathrm{~cm}^{-1}$ $\mathrm{CO}_{2}$ band, which is a good approximation of the near surface air temperature.

Calculated longwave downwelling all-sky irradiance was similar for both instruments $\left(\sim 140-141 \mathrm{~W} \mathrm{~m}^{-2}\right)$. The irradiance calculation integrates over the whole spectrum and closer examination reveals that different portions of the spectrum contributed to the irradiance from the different instrument perspectives. As previously stated, the colder air temperature measured by the P-AERI below the ice crystal cloud results in less radiance in the $600-800 \mathrm{~cm}^{-1} \mathrm{CO}_{2}$ emission band; this reduces the longwave downwelling all-sky irradiance. The increase in radiance measured by the P-AERI in the atmospheric window (the emission from the ice crystal cloud) represents an increase in longwave downwelling allsky irradiance. To determine the magnitude of this increase, the longwave downwelling irradiance from the ice crystal cloud was obtained by differencing the cloudy-sky and clearsky irradiances; the clear-sky irradiance was obtained from an LBLRTM calculation using the radiosonde temperature and $\mathrm{H}_{2} \mathrm{O}$ profiles. The longwave downwelling irradiance from the ice crystal cloud was found to be $7.8 \pm 2 \mathrm{Wm}^{-2}$ $\left(5 \mathrm{Wm}^{-2}\right.$ greater than measured by the E-AERI). This is equivalent to a $6 \% \pm 1 \%$ increase in longwave downwelling irradiance from the ice crystal cloud measured by the PAERI (below the cloud) compared to the E-AERI (above the cloud). A $6 \%$ irradiance increase for this thin cloud $(<600 \mathrm{~m}$ thick) is in agreement with the measured surface forcing of up to $36 \%$ of the downwelling longwave irradiance from thicker ice clouds ( $>2 \mathrm{~km}$ ) found in Lesins et al. (2009). Given the frequency of ice crystal events at Eureka, this can have important consequences for the surface energy balance in the Arctic region. 

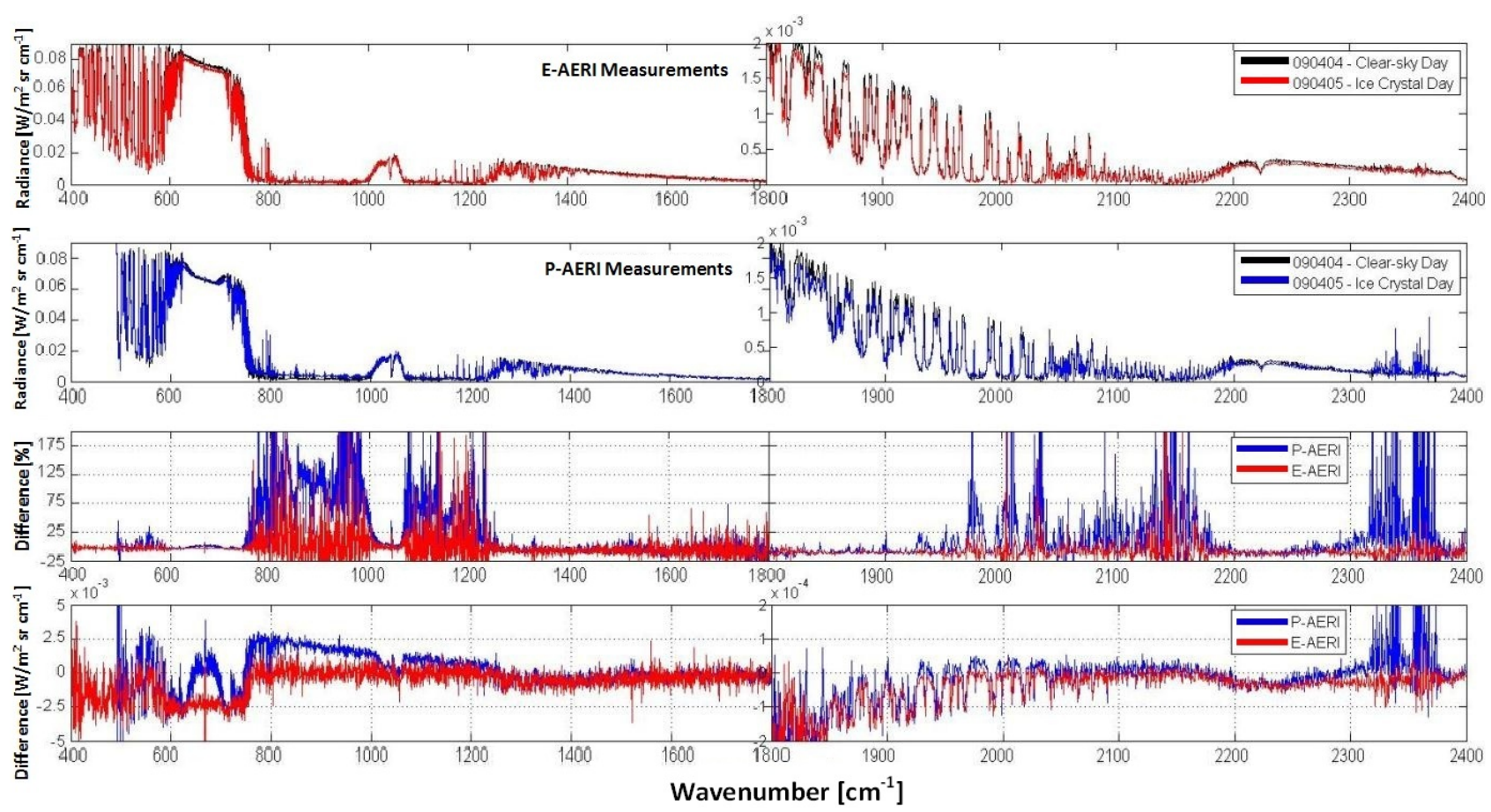

Fig. 11. Radiance measurements for 4 April 2009 (00:08-00:18 UTC) and 5 April 2009 (20:30-20:40 UTC) for the E-AERI (top panel) and P-AERI (second panel). Bottom two panels are differences between the ice crystal and clear-sky radiances, given as a percentage (ice crystal-clear sky/clear sky) and in radiance for both instruments, respectively.
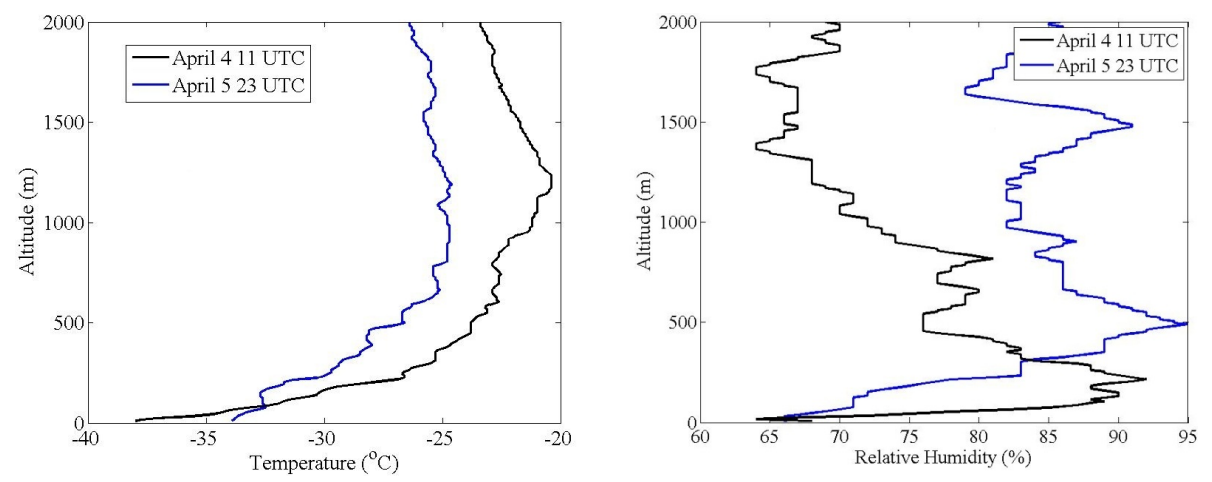

Fig. 12. Radiosonde air temperature (left panel) and relative humidity (right panel) profiles extending to 2000 m for 11:00 UTC, 4 April 2009 (black; clear-sky case), and 23:00 UTC, 5 April 2009 (blue; ice crystal cloud case).

\section{Conclusions}

A new extended-range AERI has been installed in the Canadian high Arctic. The E-AERI was calibrated and passed certification testing at the UW-SSEC in September 2008. Clearsky inter-comparison tests between the E-AERI and UW's AERI-07 and AERI-Bago indicate comparable agreement between all three instruments. The performance of the EAERI instrument meets or exceeds all initial design specifications for $1.0 \mathrm{~cm}^{-1}$ resolution infrared spectral observations with high absolute accuracy, with the exception of higher NESR values around $400 \mathrm{~cm}^{-1}$. The E-AERI was installed at PEARL in October 2008. Side-by-side comparisons with the P-AERI in cloud-free conditions indicate agreement that is comparable to results from the UW-SSEC tests over most of the E-AERI's spectral range. Infrared radiance spectra of the sky and two calibrated blackbodies have been collected continuously approximately every seven minutes year-round, including both clear-sky and cloudy conditions.

A FLBLRTM was used to simulate clear-sky radiances at two altitudes and agrees with E- and P-AERI radiances for the majority of the spectrum. The largest differences between measured and simulated radiances occur in spectral regions that are strongly influenced by atmospheric 
temperature and/or water vapour, illustrating the model's dependence on accurate meteorological data from radiosondes. The difference between the downwelling radiance at two altitudes is shown to be highly variable during the measurement overlap period for different spectral regions due to meteorological changes, such as cloud cover and temperature.

The E-AERI's measured radiance has been shown to increase by over $400 \%$ in the $750-1200 \mathrm{~cm}^{-1}$ region in the presence of clouds, correlating with the MMCR and AHSRL's detection of clouds above Eureka. This increase is larger for the Arctic than in other more humid regions, indicating that cloud cover plays a crucial role in the Arctic's radiative budget. A $6 \%$ increase in irradiance from a thin ( $<600 \mathrm{~m}$ thick) ice cloud for the P-AERI (below the cloud) and a negligible increase for the E-AERI (above the cloud) were found. This demonstrates the usefulness of the E-AERI and P-AERI measurements for investigating the impact of clouds on the Arctic radiation budget. Future detailed investigation of periods of large differences in the P-AERI - EAERI radiances is planned to further investigate the impact of different meteorological events on the radiative budget in the high Arctic.

The E-AERI observations will provide a climatology of the infrared radiation budget and total columns of trace gases. For a comprehensive investigation of the radiative exchange in the Arctic, the E-AERI is supported by the AHSRL and MMCR, as well as an aerosol photometer suite and Baseline Surface Radiation Network (BSRN) instrumentation, all located at PEARL.

Acknowledgements. The Polar Environment Atmospheric Research Laboratory (PEARL) is operated by the Canadian Network for the Detection of Atmospheric Change (CANDAC). CANDAC/PEARL funding partners are: the Arctic Research Infrastructure Fund, Atlantic Innovation Fund/Nova Scotia Research Innovation Trust, Canadian Foundation for Climate and Atmospheric Science, Canadian Foundation for Innovation, Canadian Space Agency (CSA), Environment Canada (EC), Government of Canada International Polar Year, Natural Sciences and Engineering Research Council (NSERC), Ontario Innovation Trust, Ontario Research Fund, Indian and Northern Affairs Canada, and the Polar Continental Shelf Program. Spring visits to PEARL were made as part of the Canadian Arctic ACE Validation Campaigns, led by Kaley A. Walker and supported by CSA, EC, NSERC and the Northern Student Training Program. Thanks to CANDAC operators Ashley Harrett, Alexei Khmel, Paul Loewen, Oleg Mikhailov, Keith MacQuarrie and Matt Okraszewski who have helped with the P-AERI and E-AERI measurements at PEARL. Thanks to Stephane Lantagne from ABB Bomem for his work installing the E-AERI at PEARL. Thanks also to the staff at the Eureka Weather Station for their support and hospitality.

Edited by: J. Notholt

\section{References}

Batchelor, R., Strong, K., Lindenmaier, R., Mittermeier, R., Fast, H., Drummond, J. R., and Fogal, P.: A New Bruker IFS 125HR FTIR Spectrometer for the Polar Environment Atmospheric Research Laboratory at Eureka, Nunavut, Canada: Measurements and Comparison with the Existing Bomem DA8 Spectrometer, J. Atmos. Ocean. Tech., 26, 1328-1340, 2009.

Clough, S. A., Kneizys, F. X., and Davies, R. W.: Line shape and the water vapor continuum, Atmos. Res., 23, 229-241, 1989.

Clough, S. A., Iacono, M., and Moncet, J.-L.: Line-by-line calculations of atmospheric fluxes and cooling rates: Application to water vapour, J. Geophys. Res., 97, 15761-15785, 1992.

Clough, S. A., Shephard, M. W., Mlawer, E. J., Delamere, J. S., Iacono, M. J., Cady-Pereira, K., Boukabara, S., and Brown, P. D.: Atmospheric radiative transfer modeling: a summary of the AER codes, J. Quant. Spectrosc. Ra., 91, 233-244, 2005.

Collard, A. D., Ackerman, S. A., Smith, W. L., Ma, H. E., Revercomb, H. E., Knuteson, R. O., and Lee, S. C.: Cirrus cloud properties derived from high spectral resolution infrared spectrometry during FIRE II, Part III: Ground-based HIS results, J. Atmos. Sci., 52, 4264-4275, 1995.

Cox, C., Walden, V., and Rowe, P.: A comparison of the atmospheric conditions at Barrow, Alaska and Eureka, Canada (20062008), submitted to J. Geophys. Res. on 11 November 2011, currently in review process, 2011.

DeSlover, D. H., Smith, W. L., Piironen, P. K., and Eloranta, E. W.: A methodology for measuring cirrus cloud visible-to-infrared spectral optical depth ratios, J. Atmos. Ocean. Tech., 16, 251262, 1999.

DOE: Atmospheric Radiation Measurement Program plan, US Department of Energy, DOE/ER-0442 and DOE/ER-0441, Washington, DC, 135 pp., 1990.

Ellingson, R. and Wiscombe, W.: The Spectral Radiance Experiment (SPECTRE): Project description and sample results, B. Am. Meteorol. Soc., 77, 1967-1985, 1996.

Eloranta, E. W.: High spectral resolution lidar, in: Lidar: RangeResolved Optical Remote Sensing of the Atmosphere, edited by: Weitkamp, K., Springer Series in Optical Sciences, SpringerVerlag, 143-163, 2005.

Feltz, W., Smith, W., Knuteson, R., Revercomb, H., Woolf, H., and Howell, H.: Meteorological applications of temperature and water vapor retrievals from the ground-based Atmospheric Emitted Radiance Interferometer (AERI), J. Appl. Meteorol., 37, 857875, 1998.

Gero, P. J. and Turner, D. D.: Long-term trends in downwelling spectral infrared radiance over the U.S. Southern Great Plains, B. Am. Meteorol. Soc., 24, 4831-4843, 2011.

Knuteson, R., Revercomb, H., Best, F., Ciganovich, N., Dedecker, R., Dirkx, T., Ellington, S., Feltz, W., Garcia, R., Howell, H., Smith, W., Short, J., and Tobin, D.: Atmospheric Emitted Radiance Interferometer, Part I: Instrument Design, J. Atmos. Ocean. Tech., 21, 1763-1776, 2004a.

Knuteson, R., Revercomb, H., Best, F., Ciganovich, N., Dedecker, R., Dirkx, T., Ellington, S., Feltz, W., Garcia, R., Howell, H., Smith, W., Short, J., and Tobin, D.: Atmospheric Emitted Radiance Interferometer, Part II: Instrument Performance, J. Atmos. Ocean. Tech., 21, 1777-1789, 2004b. 
Lesins, G., Bourdages, L., Duck, T. J., Drummond, J. R., Eloranta, E. W., and Walden, V. P.: Large surface radiative forcing from topographic blowing snow residuals measured in the High Arctic at Eureka, Atmos. Chem. Phys., 9, 1847-1862, doi:10.5194/acp9-1847-2009, 2009.

Minnett, P. J., Knuteson, R., Best, F., Osborne, B., Hanafin, J., and Brown, O.: The Marine-Atmospheric Emitted Radiance Interferometer (M-AERI), a high-accuracy, seagoing infrared spectroradiometer, J. Atmos. Ocean. Tech., 18, 994-1013, 2011.

Olson, J., Van Allen, J., Fogal, P., Murcray, F., and Goldman, A.: Calibrated $0.1-\mathrm{cm}^{-1}$ IR emission spectra from 80N, Appl. Optics, 35, 2797-2801, 1996.

Pougatchev, N., Connor, B., and Rinsland, C.: Infrared measurements of the ozone vertical distribution above Kitt Peak, J. Geophys. Res., 100, 16689-16697, 1995.

Rathke, C., Fischer, J., Neshyba, S., and Shupe, M.: Improving IR cloud phase determination with 20 microns spectral observations, Geophys. Res. Lett., 29, 1209, doi:10.1029/2001GL014594, 2002.

Revercomb, H., Buijs, H., Howell, H., LaPorte, D., Smith, W., and Sromovsky, L.: Radiometric calibration of IR Fourier transform spectrometers: Solution to a problem with the High-Resolution Interferometer Sounder, Appl. Optics, 27, 3210-3218, 1988.

Rinsland, C. P., Jones, N., Connor, B., Logan, J., Pougatchev, N., Goldman, A., Murcray, F., Stephen, T., Pine, A., Zander, R., Mahieu, E., and Demoulin, P.: Northern and Southern Hemisphere ground-based infrared spectroscopic measurements of tropospheric carbon monoxide and ethane, J. Geophys. Res., 103, 28197-28217, 1998.

Rothman, L., Gordon, I., Barbe, A., Chris Benner, D., Bernath, P., Birk, M., Boudon, V., Brown, L., Campargue, C., Champion, J., Chance, K., Coudert, L., Dana, V., Devi, V., Fally, S., Flaud, J.-M., Gamache, R. R., Goldman, A., Jacquemart, D., Kleiner, I., Lacome, N., Lafferty, W. J., Mandin, J.-Y., Massie, S. T., Mikhailenko, S. N., Miller, C. E., Moazzen-Ahmadi, N. Naumenko, O. V., Nikitin, A. V., Orphal, J., Perevalov, Smith, V. I., Perrin, A., Predoi-Cross, A., Rinsland, C. P., Rotger, M., Simeckova, M., M. A. H., Sung, K., Tashkun, S. A., Tennyson, J., Toth, R. A., Vandaele, A. C., and Vander Auwera, J.: The HITRAN 2008 molecular spectroscopic database, J. Quant. Spectrosc. Ra., 110, 533-572, 2009.

Rowe, P., Miloshevich, L., Turner, D., and Walden, V.:: Quantification of a dry bias in radiosonde humidity profiles over Antarctica, J. Atmos. Ocean. Tech., 25, 1529-1541, 2008.

Rowe, P., Neshyba, S., and Walden, V.:: Responsivity-based criterion for accurate calibration of FTIR emission spectra: theoretical development and bandwidth estimation, Opt. Express, 19, 5451-5463, 2011a.

Rowe, P., Neshyba, S., Cox, C., and Walden, V.: A responsivitybased criterion for accurate calibration of FTIR emission spectra: identification of in-band low-responsivity wavenumbers, Opt. Express, 19, 5930-5941, 2011b.
Schneider, M., Romero, P. M., Hase, F., Blumenstock, T., Cuevas, E., and Ramos, R.: Continuous quality assessment of atmospheric water vapour measurement techniques: FTIR, Cimel, MFRSR, GPS, and Vaisala RS92, Atmos. Meas. Tech., 3, 323338, doi:10.5194/amt-3-323-2010, 2010.

Shaw, J., Nugent, P., Pust, N., Thurairajah, B., and Mizutani, K.: Radiometric cloud imaging with an uncooled microbolometer thermal infrared camera, Opt. Express, 13, 5807-5817, 2005.

Smith, W. L., Feltz, W. F., Knuteson, R. O., Revercomb, H. B., Howell, H. B., and Woolf, H. M.: The retrieval of planetary boundary layer structure using ground-based infrared spectral radiance measurements, J. Atmos. Ocean. Tech., 16, 323-333, 1999.

Stokes, G. M. and Schwartz, S. E.: The Atmospheric Radiation Measurement (ARM) Program: Programmatic background and design of the Cloud and Radiation Testbed, B. Am. Meteorol. Soc., 75, 1201-1221, 1994.

Tobin, D., Best, F., Brown, P., Clough, S., Dedecker, R., Ellingson, R., Garcia, R., Howell, H., Knuteson, R., Mlawer, E., Revercomb, H., Short, J., van Delst, P., and Walden, V.: Downwelling spectral radiance observations at the SHEBA ice station: Water vapor continuum measurements from 17 to $26 \mu \mathrm{m}$, J. Geophys. Res., 104, 2081-2092, 1999.

Turner, D. D.: Arctic mixed-phase cloud properties from AERIlidar observations: Algorithm and results from SHEBA, J. Appl. Meteorol., 44, 427-444, 2005.

Turner, D. D. and Gero, P. J.: Downwelling 10-micron infrared radiance temperature climatology for the Atmospheric Radiation Measurement Southern Great Plains site, J. Geophys. Res., 116, D08212, doi:10.1029/2010JD015135, 2011.

Turner, D. D., Feltz, W. F., and Ferrare, R. A.: Continuous water vapor profiles from operational ground-based active and passive remote sensors, B. Am. Meteorol. Soc., 81, 1301-1317, 2000.

Turner, D. S.: Absorption Coefficient Estimation Using A Two Dimensional Interpolation Procedure, J. Quant. Spectrosc. Ra., 53, 633-637, 1995.

UW-SSEC: UW Final Report on ABB-Bomem E-AERI-001; Certification Testing, 9 December 2008, University of Wisconsin, 1-12 pp., 2008.

Vavrus, S.: The Impact of Cloud Feedbacks on Arctic Climate under Greenhouse Forcing, J. Climate, 17, 603-615, 2004.

Walden, V. P., Town, M., Halter, B., and Storey, J.: First measurements of the infrared sky brightness at Dome C, Antarctica, Publ. Astron. Soc. Pac., 117, 300-308, 2005.

Yurganov, L., McMillan, W., Wilson, C., Fischer, M., Biraud, S., and Sweeney, C.: Carbon monoxide mixing ratios over Oklahoma between 2002 and 2009 retrieved from Atmospheric Emitted Radiance Interferometer spectra, Atmos. Meas. Tech., 3, 1319-1331, doi:10.5194/amt-3-1319-2010, 2010. 